\title{
DO FORMALISMO ÉTICO AO TRIBUNAL DA HISTÓRIA: REFLEXÕES SOBRE FILOSOFIA PRÁTICA EM KANT E HEGEL
}

FROM ETHICAL FORMALISM TO THE COURT OF HISTORY: REFLECTIONS ON PRACTICAL PHILOSOPHY IN KANT AND HEGEL

SALVADORI, Mateus. Metafísica e filosofia prática: Hegel e o formalismo kantiano. Curitiba: Prismas, 2017. 249 p.

Moisés João Rech ${ }^{*}$

Aquele que se põe, com seriedade, a subir as grandes cordilheiras do pensamento filosófico depara-se, inexoravelmente, com as obras dos maiores expoentes da filosofia moderna: Immanuel Kant e Georg W. H. Hegel. O desafio intelectual de Mateus Salvadori é proporcional à profundidade filosófica das obras que busca analisar: da Crítica da razão pura à Fenomenologia do espírito, e da Crítica da razão prática aos Princípios de filosofia do direito. Mas à guisa das dificuldades dos textos kantianos e hegelianos, Salvadori conserva um estilo objetivo, claro e conceitualmente preciso, o que revela sua competência intelectual.

A obra é resultado das pesquisas de doutoramento em que o autor se lança à questão: "o 'direito de dizer não', como instância mediadora das determinações ético-políticas, a fundamentação ética e não formal da Constituição e o tribunal da história, como critério de justiça não formal, superam uma teoria da justiça formalista?” (2017, p. 24). A questão expõe a ambiciosa tese: "pensar a justiça e o direito vinculados com a liberdade e com a história" (2017, p. 29). Assim, Salvadori traça sua meta de analisar comparativamente os dois maiores filósofos da modernidade: Kant e Hegel.

Para isso, o texto divide-se em duas partes, compostas por sete capítulos. A primeira parte engloba os três primeiros capítulos e tem como tema a Metafísica e a Teoria do Conhecimento para ambos os autores. A segunda parte, que é composta por mais quatro capítulos, segue analisando o pensamento de Kant e Hegel, mas com o arcabouço teórico até então revisitado. Assim, a segunda parte trata de Filosofia Prática, e destina-se a responder a questão posta pelo autor: teria Hegel, com seu ethos e seu tribunal da história, superado o formalismo kantiano?

\footnotetext{
* Mestre e Bacharel em Direito pela Universidade de Caxias do Sul (UCS). Professor do curso de Bacharelado em Direito da Universidade de Caxias do Sul (UCS). E-mail: mjrech7@gmail.com.
} 
$\mathrm{O}$ texto inicia com o capítulo intitulado "O idealismo transcendental kantiano e a impossibilidade da metafísica como ciência", o qual se debruça sobre o idealismo transcendental exposto na Crítica da razão pura, por meio da questão fundamental elaborada por Kant a respeito da existência de juízes sintéticos a priori. Com esse objetivo, Salvadori expressa sua capacidade de síntese ao expor as grandes questões da filosofia kantiana de modo claro e conceitualmente preciso.

O ponto de partida de Kant é sua desconfiança para com a Metafísica, que se pretendia universal, mas "era incapaz de oferecer soluções unanimemente aceitas" (SALVADORI, 2017, p. 32). Com essa questão, Kant procura compreender se a Metafísica encontra-se no campo das ciências - com leis universais e necessárias -, as quais a razão pode conhecer, ou está para além de qualquer conhecimento possível. Para tanto, Kant ataca o problema pela raiz, ao questionar os próprios limites da razão ao focar na questão das condições de possibilidade do conhecimento.

Para elaborar sua resposta, Kant realiza a síntese entre duas tradições filosóficas opostas: o racionalismo de Descartes e Leibniz, e o empirismo de Locke e Hume. Os racionalistas sustentam que o conhecimento científico é oriundo de juízos analíticos a priorisem contato com a experiência; enquanto os empiristas afirmam o inverso: apenas juízos sintéticos a posteriori podem gerar conhecimento científico - pois não há nada transcendental à experiência. Contudo, destaca Kant que "o conhecimento não surge somente com o sujeito ou somente com o objeto, mas surge da junção dos dois, ou seja, o conhecimento é resultado de um elemento a priori - sujeito -, e de um elemento a posteriori - objeto" (SALVADORI, 2017, p. 37).

Portanto, o conhecimento, isto é, os limites da razão, são dados pela união de sujeito e objeto; mas não uma união incondicional: existem limites para a razão. Esses limites são dados pelo próprio sujeito, pela sensibilidade (espaço/tempo) e pelo entendimento (categorias). Em linhas gerais, o sujeito apenas pode conhecer aquilo que "põe" no objeto, ou seja, apenas conhece objetos no espaço e no tempo, e segundo as categorias do entendimento - que são no número de doze. O "resto" apresenta-se incognoscível para o sujeito. "É impossível captar o objeto como ele é em si, mas somente como ele aparece para nós.” (p. $41)$.

Esse "resto" incognoscível é denominado por Kant de "númeno" ou de "coisa-em-si". Salvadori destaca ainda que é a partir dessa constatação que Kant limita o conhecimento à experiência sensível, estabelece a Metafísica como não científica pois seus objetos de estudo 
são suprassensíveis, e acima de tudo, a desloca para o campo da Moral. A Metafísica é agora “enquadrada em outra dimensão que não seja a da razão pura especulativa: a razão pura prática. Ela será o fundamento da moral” (p. 46). O idealismo transcendental elimina qualquer possibilidade de conhecer o Absoluto, pois estabelece a cisão intransponível entre sujeito e objeto.

A partir dessa contextualização a respeito da dualidade kantiana, Salvadori se lança a seu principal objeto de estudo: o idealismo absoluto. No segundo capítulo o foco é a Fenomenologia do espírito, e sua progressão da certeza sensível ao saber absoluto; sob o título "O idealismo absoluto e o fim das cisões entre ser e pensar", o autor demonstra novamente sua capacidade teórica com o manejo da dialética hegeliana.

Nesse capítulo, de grande densidade, Salvadori reconstrói as figuras da consciência, demonstrando suas contradições e sua passagem a estágios mais elevados. A certeza sensível tem como verdade a imediatez, isto é, o singular. "A certeza sensível, pensando que o objeto é essencial, busca o singular, mas ao tentar exprimi-lo o transforma em um universal pobre" (p. 59-60). A certeza sensível vai ao objeto ou o "isso-aí" e constata sua incapacidade de dizê-lo; assim, a certeza volta-se ao sujeito ou o "este-aqui", mas também constata que permanece no universal abstrato. Por fim, a certeza sensível constata: sua verdade está além de si.

A segunda figura da consciência, a percepção, parte do universal abstrato da certeza sensível. Porém, "a universalidade do objeto tem duas faces: a multiplicidade das propriedades e a universalidade distinta e independente das propriedades" (p. 65). Aqui, "a percepção, ao considerar o objeto como verdadeiro vacila entre a sua unidade e as várias propriedade que se manifestam nele" (p. 66), de tal forma que as propriedades da coisa revelam que ela é para-si como também para Outro. A percepção então constata que o inessencial é a coisa, e que o "essencial torna-se a relação" (p. 67).

Nesse momento o entendimento é a figura superveniente. Agora não se trata mais de pensar o objeto singularmente, em-si, trata-se de pensar a "passagem do uno-múltiplo, serpara-si-ser-para-outro, interior-exterior" (p. 69), ou seja, a relação, ou o que Hegel chama de "força". Com a força, salva-se a unidade, mas abre-se uma nova fase, a consciência descobre que para além do mundo sensível, fenomênico, há o mundo suprassensível, ou seja, um interior das coisas. Mas esse interior é o pensamento que explica o fenômeno, pois "fora do sensível não há qualquer realidade fantasmática que seria o dentro deste sensível. A lei que é esse dentro é um pensamento" (p. 71). Nesse momento, a consciência se reconhece no objeto, e torna-se consciência-de-si, ou seja, sabe que seu saber é saber de si. Salvadori segue 
analisando o movimento da consciência-de-si até tornar-se razão, na qual a consciência-de-si tem certeza de ser toda realidade - está superado o dualismo kantiano.

No capítulo terceiro, com o título "A superação do idealismo transcendental pelo idealismo absoluto", Salvadori delineia as censuras de Hegel para com as dualidades kantianas. O autor destaca a permanência de Kant no mero "entendimento", ou seja, no momento abstrato; por outro lado, Hegel faz a passagem do entendimento para a "razão", i.e., do momento abstrato para a negatividade, e além, para a identidade entre entendimento e negatividade: o positivo racional ou especulativo. É a partir desse movimento que Hegel identifica que a "raiz das contradições da filosofia kantiana está no fato de que o pensamento é movido pelo entendimento" (p. 96). Com esse capítulo é encerrado o debate de ordem gnosiológica e metafísica, para passar à análise da filosofia prática dos autores.

Nos próximos capítulos são delineadas as deficiências do formalismo moral kantiano a partir do ponto de vista do ethos hegeliano. Assim, o capítulo quarto, que trata da "justiça formal em Kant", inicia com a distinção kantiana entre arbítrio e o desejo e, dessa distinção, a conclusão de que "a razão é uma faculdade de desejar superior" (p. 107), ou seja, sem qualquer conteúdo empírico e, portanto, formal e universal. Sendo formal, a razão não prescreve nenhuma conduta, mas apenas o dever de obediência à lei moral: o imperativo categórico. Já na seção "Moralidade e legalidade", o autor reconstrói a teoria jurídica kantiana, ao destacar a fundamentação moral do direito e da ética.

A legislação jurídica tem como móbil da ação a coerção externa, enquanto que para a ética, o móbil é o dever pela lei moral. Destarte, "essa distinção entre ética e direito é essencialmente formal, pois não se preocupa com o conteúdo da ação, mas apenas com a forma” (p. 118). Após adentrar na arquitetura da filosofia prática de Kant, o autor leva o debate para o campo da justiça e, consequentemente, para o direito natural e positivo.

Para sintetizar a posição adotada pelo autor, sua interpretação leva em consideração o direito natural como fundamento do direito positivo. Enquanto o direito natural, que fundamenta-se na razão, distingue o justo do injusto, o direito positivo limita-se ao lícito e ao ilícito; porém, o critério de justiça de Kant advém do direito natural, que é igualmente formal. "Esse procedimento [...] é formal. Ele não diz o que é justo e injusto, mas apenas aponta um procedimento para alcançar a justiça.” (SALVADORI, 2017, p. 122). Novamente Kant limitase ao aspecto formal, sob o pressuposto de que o desejo inferior - os sentimentos e as paixões - é impossível de ser universalizado. Essa postura rende críticas por parte de Hegel, que são revisitadas no capítulo seguinte. 
Ao avançar na obra, o capítulo seguinte trata do "Direito e justiça em Hegel", e se inscreve na tradição do pensamento comunitarista. Ao levar em consideração os costumes, as tradições, a cultura, a religião, a arte, as leis, em suma, o espírito do povo, Hegel fornece as condições para pensar o agir justo de forma histórica e concreta. $\mathrm{O}$ autor destaca logo no início do capítulo que "somente é possível conhecer o meu dever em contextos concretos e não em um vazio formalismo" (SALVADORI, 2017, p. 143), ou seja, "o dever somente pode ser sabido dentro de um contexto mediante mediações das instituições sociais" (p. 145).

Em oposição ao contratualismo professado por Kant, Hegel expõe sua visão comunitária - de raiz aristotélica - da formação social. Essa postura inverte a lógica contratualista: a liberdade não é algo inato ao homem, mas uma conquista social. A comunidade é anterior ao indivíduo, e o indivíduo se constitui como tal a partir do reconhecimento. Nesse caso, o atomismo de Hobbes e Maquiavel é contraditado pela comunidade - a polis grega -, e a luta por autoconservação pelo reconhecimento intersubjetivo.

No desenvolvimento de sua exposição, Salvadori adentra no campo da teoria da punição hegeliana, em razão de que pensar a justiça é levar em consideração a punição. A via da cura e da expiação está presente no Direito Abstrato, primeira parte dos Princípios de filosofia do direito, e constituem a posição de Hegel sobre a questão da punição do crime. Salvadori destaca que na via da expiação, a pena é vista como uma punição compensatória do sofrimento da vítima, o que demonstra um viés retributivista. Por outro lado, a via da cura toma o agente do crime como doente, e necessita ser curado. "Atribuir o sentido da cura à punição é considerar o criminoso um infeliz, um doente que tem a possibilidade de curar-se." (p. 164).

A via da expiação afirma que castigar o criminoso não é uma injustiça, mas uma forma de anular o mal causado e restabelecer a ordem jurídica. O autor esclarece que para Hegel "a pena tem como função restabelecer a ordem transgredida do direito (retributivismo) e recuperar a honra do criminoso" (p. 165). Portanto, o crime é a negação do direito, e o castigo é a negação da negação do direito: a reconciliação da ordem jurídica enquanto vontade geral.

Encaminhando-se para o último capítulo, sob o título "Para além da justiça formal", Salvadori trata a questão central da filosofia prática de Hegel: a eticidade. Aqui tornam-se mais concretas as respostas à sua problemática de pesquisa, pois "a eticidade hegeliana é a resposta aos problemas gerados pela concepção formal do direito e da justiça em Kant" (p. 185). A eticidade, ou moralidade objetiva, "é a mediação social da vontade livre enquanto 
princípio orientador" (p. 185), e resulta do movimento de superação do Direito Abstrato e da Moralidade.

Na eticidade, as instâncias mediadoras das determinações ético-políticas são a família, os estamentos, as corporações, a opinião pública e o "direito de dizer não". A família é a base do Estado, mas é com sua dissolução que o indivíduo torna-se membro de uma corporação, e pertence à sociedade civil - a segunda base do Estado. Nesse momento Salvadori destaca que é impossível que todos os indivíduos sejam participantes da corporação burocrata estatal, porém, é por meio da opinião pública que torna-se possível a todos expressar sua opinião sobre o Estado e sobre as decisões de governo - sobre as decisões da classe burocrata.

Com a opinião pública "os cidadãos se formam e informam. [...]. Quando o povo está bem-informado, não é possível manipulá-lo" (p. 194-195). Destarte, a opinião pública tem a função de formação política do cidadão, e por meio dela utiliza-se o "direito de dizer não", ou seja, a desobediência civil. "O que não se quer é um poder sendo exercido de forma despótica e totalitária. [...] Por isso, o 'direito de dizer não' é essencial para os cidadãos superarem a atuação injusta do Estado.” (p. 196). Quando o Estado comete um exagero, ao povo cabe opor-se a essa decisão pelo direito de dizer não. "Caso a lei esteja a favor do injusto, os cidadãos têm a possibilidade, por meio do 'direito de dizer não', de não aceitar a lei injusta e se opor a ela." (p. 199).

A penúltima e a última seção do último capítulo são, respectivamente, "Uma fundamentação ética e não formal da Constituição" e "O tribunal da história como critério de justiça não formal"; constituem o coração da tese do autor: o desenvolvimento de um critério substancial de justiça. Essas duas seções convergem para uma finalidade em comum, a de responder ao problema de pesquisa posto pelo autor.

A concepção hegeliana de Constituição é a própria organização do Estado, i.e., o organismo político e não um documento escrito. A Constituição ético-política representa, portanto, o ethos de um povo, ou o que Hegel chama de "espírito do povo". Essa posição alinha-se com a crítica de Hegel ao formalismo de Kant, em razão da impossibilidade de se pensar a priori princípios universais aplicáveis em qualquer situação. Cada povo tem sua cultura, e a universalidade é alcançada pela mediação de indivíduos e instituições de acordo com cada contexto social. Dessa forma, a vida orgânica do Estado - a Constituição - possui um fundamento ético.

Na última seção, Salvadori introduz um instigante debate a respeito das interpretações do sistema de Hegel: a necessitarista e a contingencialista, e posiciona-se a favor da segunda. 
Ao assumir a posição da contingência, o sistema hegeliano abre-se para a liberdade, categoria central do desenvolvimento histórico, ou seja, do desdobramento do conceito. Porém, "a liberdade só se realiza na vontade humana, e essa se origina no espírito" (p. 221). Mas a densidade da explanação não deixa dúvidas: o movimento histórico, i.e., do pensamento, leva consigo o movimento da efetividade do concreto: os princípios éticos são resultado do desdobramento histórico e das mediações presentes nas sociedades, e não fruto do pensamento a priori.

O tribunal da história, ou o "espírito do mundo", constitui o critério de justiça substancial, promovendo o universal concreto, em detrimento do imperativo categórico kantiano que permanece no universal abstrato. "O contexto, a comunidade ética, e o $a$ posteriori ganham importância ao se tratar do ético, da moral e do jurídico. [...]. Quando se trata da justiça, do direito e da política, é necessário defender as mediações por meio das instituições sociais.” (p. 240).

A obra em questão merece ser reconhecida, tanto por sua profundidade teórica, como por sua contribuição para o público brasileiro a respeito das filosofias hegeliana e kantiana. A contribuição é mais relevante quando leva-se em consideração a complementação entre teoria do conhecimento e filosofia prática presente na obra de Salvadori. A leitura é recomendada para aqueles que buscam conhecer ou aprofundar os estudos sobre o idealismo alemão, especialmente em Kant e Hegel. 